ISSN 2236-0859

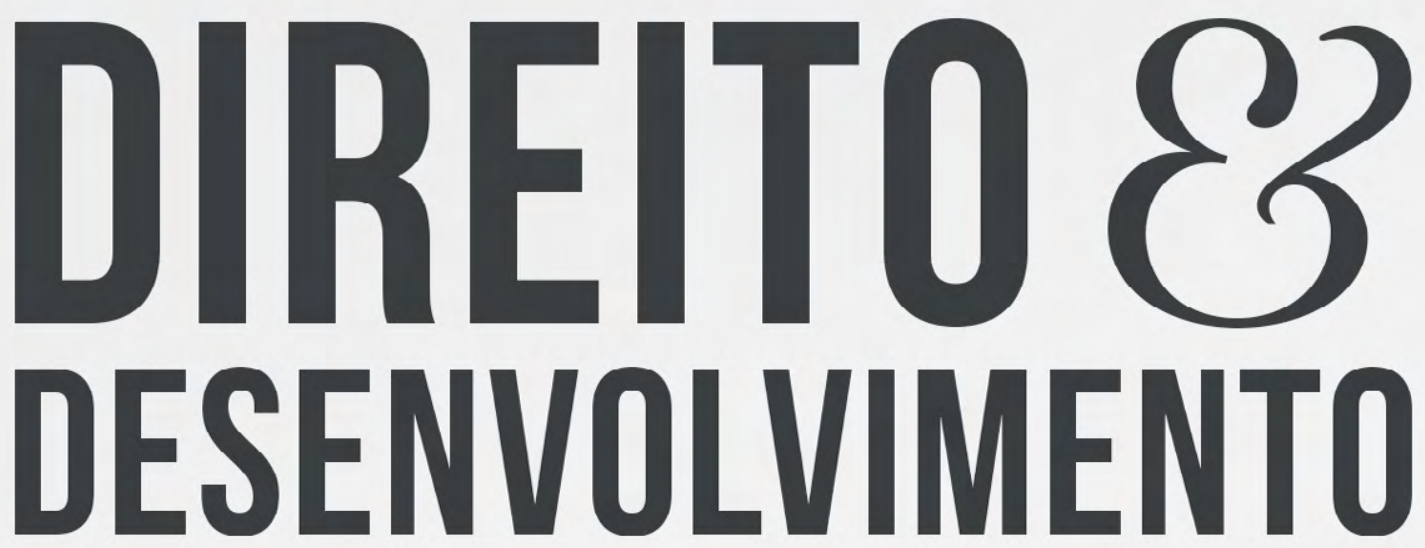

REVISTA DO PROGRAMA DE PÓS-GRADUAÇÃO EM DIREITO MESTRADO EM DIREITO E DESENVOLVIMENTO SUSTENTÁVEL

O CONTRATO NATURAL COMO ALTERNATIVA PARA A EFETIVIDADE DAS UTOPIAS CONCRETAS SULAMERICANAS: OCASO DA UNASUL

SÉRGIO RICARDO FERNANDES DE AQUNNO 


\title{
O CONTRATO NATURAL COMO ALTERNATIVA PARA A EFETIVIDADE DAS UTOPIAS CONCRETAS SUL-AMERICANAS: O CASO DA UNASUL
}

\section{NATURAL CONTRACT AS AN ALTERNATIVE TO THE EFFECTIVENESS OF THE SOUTH AMERICAN REAL UTOPIAS: THE CASE OF UNASUL}

Recebido: $15 / 02 / 2018$

Aprovado: 25/03/2018

Sérgio Ricardo Fernandes de Aquino*

RESUMO: Esta pesquisa busca esclarecer os fundamentos de uma utopia concreta entre o Homem e a Natureza na qual ganha outro significado a partir da UNASUL: O Contrato Natural. O objetivo geral é investigar como o Contrato Natural se apresenta como instrumento apto a retratar o pacto entre seres humanos e a Terra, exemplificado, nesta pesquisa, pelo Tratado Constitutivo da União De Nações SulAmericanas. O método utilizado foi o Dedutivo. Nas conclusões, verifica-se que a unidade de uma integração continental não se realiza por meio da egoísta postura antropocêntrica, mas, aos poucos, pelo desvelo responsável de outra: a biocêntrica.

Palavras-chave: América do Sul. Contrato Natural. Utopia Concreta. UNASUL.

\begin{abstract}
This paper tries to clarify the fundamentals of real utopias between Man and Nature in which it gains another meaning from The Natural Contract in the context of UNASUR. The objective is to investigate how the Natural Contract presents itself as an instrument capable of portraying the pact between humans and the Earth, exemplified in this research by the Constitutive Treaty of the Union of South American Nations. The method used was the Deductive. In the conclusions, it's possible to find that the integration in South America is not realized through the anthropocentric attitude, but, gradually, by the responsible awakening of another: the biocentric one.
\end{abstract}

Keywords: South America. Natural Contract. Real Utopia. UNASUR.

*Doutor e Mestre em Ciência Jurídica pela Universidade do Vale do Itajaí - UNIVALI. Professor Permanente e Pesquisador do Programa de Pós-Graduação Stricto Sensu - Mestrado- em Direito da Faculdade Meridional - IMED. Coordenador do Grupo de Pesquisa: Ética, Cidadania e Sustentabilidade. E-mail: sergiorfaquino@gmail.com 


\section{INTRODUÇÃO}

A criação de um projeto racional como o Contrato Social oportunizou a valorização da Liberdade como pressuposto comum a todos os seres humanos. Convenciona-se estabelecer a submissão da vontade individual pela geral a fim de garantir uma perfeita união entre as pessoas e garantir cenários mais pacíficos.

Dissemina-se, nessa linha de pensamento, a necessidade de direitos que assegurem o exercício e a reivindicação da Dignidade Humana, especialmente quando essa não existir nas relações humanas ou for subtraída, seja por atos dos próprios associados ou do soberano. A única autoridade legítima definida por esse pacto é a vontade geral.

Quando, historicamente, as sociedades se aperfeiçoam e se tornam mais complexas, o Contrato Social não possibilita a conservação das relações humanas, porque essas, agora, ultrapassam os limites da postura antropocêntrica e demandam outras mais significativas, especialmente aquelas nas quais resgatam a partilha de um vínculo biológico comum.

Percebe-se, nesses argumentos, uma transição do Contrato Social ao Contrato Natural como expressão utópica de consolidação dessa relação amistosa e proxêmica no sentido de se elaborar, no caso deste estudo, uma integração sul-americana. O Tratado Constitutivo da UNASUL representa, portanto, a materialização do Contrato Natural.

A partir desses argumentos, o critério metodológico utilizado para a investigação de abordagem e a base lógica do relato dos resultados apresentados reside no Método Dedutivo², cuja premissa maior é a passagem do Contrato Social ao Contrato Natural e a premissa menor se manifesta pela caracterização e aplicação do Contrato Natural na UNASUL. As técnicas utilizadas nesse estudo serão a Pesquisa Bibliográfica ${ }^{3}$, a Categoria ${ }^{4}$ e o Conceito Operacional'5.

O problema de pesquisa formulado para este estudo pode ser descrito pela seguinte indagação: $\mathrm{O}$ Tratado Constitutivo da União de Nações Sul-Americanas - UNASUL - se caracteriza como contrato social ou contrato natural? A hipótese para essa pergunta surge, inicialmente, como positiva, na medida em que se observam insuficiências históricas e racionais capazes de acolher as interações humanas com o mundo natural apresentadas pelo Contrato Social de Rousseau.

O pacto entre todos que habitam a Terra amplia-se pela compreensão ${ }^{6}$ desse vínculo necessário e ambivalente, pois a preservação de todos os seres vivos os quais habitam essa "casa comum" denota participação, mas representa, antes, uma razão seminal, interior, a qual resgata a necessidade de um profundo exercício de Alteridade ${ }^{7}$ no mundo, cujo fundamento não se exaure na postura antropocêntrica.

O Objetivo Geral deste estudo é determinar como o Contrato Natural se apresenta como

\footnotetext{
2 Para Pasold, trata-se da "[...] base lógica da dinâmica da Pesquisa Científica que consiste em estabelecer uma formulação geral e, em seguida, buscar as partes do fenômeno de modo a sustentar a formulação geral”. (PASOLD, 2011, p. 205).

3 Segundo o mencionado autor: “[...] Técnica de investigação em livros, repertórios jurisprudenciais e coletâneas legais." (PASOLD, 2011, p. 207). 4 Nas palavras de Pasold: “[...] palavra ou expressão estratégica à elaboração e/ou expressão de uma idéia”. (PASOLD, 2011, p. 25). Grifos originais da obra em estudo.

5 Reitera-se conforme Pasold: "[...] uma definição para uma palavra ou expressão, com o desejo de que tal definição seja aceita para os efeitos das idéias que expomos [...]". (PASOLD, 2011, p. 37). Grifos originais da obra em estudo. Toda Categoria que aparece neste estudo será destacada com letra maiúscula.

$6 \mathrm{O}$ verbo compreender terá como significado nessa pesquisa o conceito proposto por Morin: "Há duas formas de compreensão: a compreensão intelectual ou objetiva e a compreensão humana intersubjetiva. Compreender significa intelectualmente apreender em conjunto, comprehendere, abraçar junto (o texto e seu contexto, as partes e o todo, o múltiplo e o uno). A compreensão intelectual passa pela inteligibilidade e pela explicação. [...] A compreensão humana vai além da explicação. A explicação é bastante para a compreensão intelectual ou objetiva das coisas anônimas ou materiais. É insuficiente para a compreensão humana. Esta comporta um conhecimento de sujeito a sujeito. [...] Compreender inclui, necessariamente, um processo de empatia, de identificação e projeção. Sempre intersubjetiva, a compreensão pede abertura, simpatia e generosidade”. (MORIN, 2001, p. 94/95).

7 Trata-se de relação da subjetividade com o infinito, ou seja, da subjetividade que acolhe o Outro. A ideia do infinito, conforme Lévinas, "[...] não é uma noção que uma subjectividade forje casualmente para reflectir uma entidade que não encontra fora de si nada que a limite, que ultrapassa todo limite e, por isso, infinita. A produção da entidade infinita não pode separar-se da ideia do infinito, porque é precisamente na desproporção entre a ideia do infinito de que ela é ideia que se produz a ultrapassagem dos limites. A ideia do infinito éo modo de ser - a infinição do infinito. O infinito não existe antes para se revelar depois. A sua infinição produz-se como revelação, como uma colocação em mim da sua ideia. Produz-se no facto inverossímil em que um ser separado fixado na sua identidade, o Mesmo, o Eu contém, no entanto, em si - o que não pode nem conter, nem receber apenas por força de sua identidade. A subjectividade realiza essas exigências impossíveis; o facto surpreendente de conter mais do que é possível conter". (LÉVINAS, 200o, p. 14).
} 
instrumento apto a retratar o pacto entre seres humanos e a Terra, exemplificado, nesta pesquisa, pelo Tratado Constitutivo da União De Nações Sul-Americanas - UNASUL.

Os Objetivos Específicos são: a) Esclarecer a importância histórica do Contrato Social; b) Definir o queéo Contrato Natural; c) Avaliar a necessária integração - e cooperação - entre os seres humanos e a Terra que os acolhe; d) Identificar a integração sul-americana como estratégia geopolítica de reconhecimento da natureza como ser próprio; e); f) Reconhecer as insuficiências históricas do Contrato Social para a Eficácia ${ }^{8}$ e Eficiência9 para expressar outros pactos como o Contrato Natural.

Os referenciais teóricos deste artigo são expressos pelo pensamento de autores como Rousseau, Serres, Bloch, Huanacuni, entre outros. Buscam-se, ainda, outras leituras as quais apresentam diferentes percepções sobre o tema em estudo para elucidar o(s) significado(s) e contexto(s) de determinadas categorias apresentadas neste estudo.

\section{A RAZÃO VENCEU! REFLEXÕES SOBRE CONTRATO SOCIAL DE ROUSSEAU}

O pensamento político de Jean-Jacques Rousseau ${ }^{10}$ é estimulado pelo esclarecimento luminoso da Razão" a fim de se propor uma vida comum pautada na paz. Aos poucos, se observa a materialização do projeto fundado pela ciência, pela técnica como princípio civilizador da Modernidade.

Entretanto, na época de Rousseau, não se contempla, ainda, a obsessão da racionalização ${ }^{12}$, ou, sob um ângulo diferente, a transição (ou substituição) da Razão para a Razão Instrumental ${ }^{13}$. Por esse motivo, os espaços destinados ao conhecimento, de dúvidas fomentadas pela Razão, persistem na tentativa de esclarecer o que é esse vínculo antropológico comum o qual deve ser reconhecido e preservado.

A leitura da obra de Rousseau denota preocupação no sentido do Direito ${ }^{14}$ estabelecer quais pressupostos ampliam e asseguram, nos limites do Estado nacional, a Dignidade ${ }^{15}$ Humana. A teoria política do mencionado autor não cria clausuras abstratas para se distanciar das necessidades - inclusive morais - dos homens, mas associa o exercício da liberdade política às condições necessárias para o desenvolvimento da existência. Segundo a linha de pensamento de Rousseau, não é possível haver justiça - tampouco sua utilidade - se aquilo que o direito admite não estiver em concordância com o que o direito prescreve (ROUSSEAU, 2013, p. 21).

8 A categoria refere-se aos resultados desejados. (PASOLD, 2011, p. 201)

9 Trata-se da utilização de todos os recursos técnicos disponíveis ao cumprimento de um possível resultado desejado. (PASOLD, 2011, p. 201). 10 Cunha destaca, brevemente, alguns aspectos da vida de Rousseau: "Órfão de mãe e abandonado por um pai em fuga (esse pai relojoeiro que lhe contava histórias para adormecer), Jean-Jacques Rousseau teve uma vida atribulada de autodidacta, Sensível, eloquente, sonhador, talentoso, cativou muitos em vida e depois dela, embora se sentisse perseguido e mal-amado. Autor de um novo sistema de notação musical e compositor de uma ópera, premiado no concurso da Academia de Dijon com seu Discurso sobre as ciências e as artes, escreveu muito, desde romances filosóficos a inúmeras cartas, obras políticas e pedagógicas...Protegido dos grandes, morreu pobre". (CUNHA, 2010, p. 311).

11 "[...] Referencial de orientação do homem em todos os campos em que seja possível a indagação ou a investigação. Nesse sentido, dizemos que a R. é uma 'faculdade própria do homem, que o distingue dos animais”. (ABBAGNANO, 2003, p. 824).

12 Nas palavras de Touraine, a racionalização aparece como único princípio que organiza a vida individual e coletiva na Modernidade. (TOURAINE, 2002, p. 18).

13 representa "[...] o tipo de racionalidade a que recorremos quando ponderamos a aplicação dos meios mais simples para chegar a um dado fim. A máxima eficiência, a melhor ratio custo-produção, é a medida do sucesso”. (TAYLOR, 2009, p. 20).

${ }_{14}$ Categoria multidisciplinar que se revela como “[...] compreensão [...] in acto, como efetividade de participação ede comportamentos, sendo, essencial ao seu conceito a vivência atual do direito, a concreta correspondência das formas da juridicidade ao sentir e querer, ou às valorações da comunidade". (REALE, 2010, p. 31). Grifos da obra original em estudo

15 "A dignitas é um atributo que se confere ao indivíduo desde fora e desde dentro. A dignidade tem a ver com o que se confere ao outro (experiência desde fora), bem como com o que se confere a si mesmo (experiência desde dentro). A primeira tem a ver com o que se faz, o que se confere, o que se oferta [...] para que a pessoa seja dignificada. A segunda tem a ver com o que se percebe como sendo a dignidade pessoal, com uma certa auto-aceitação ou valorização-de-si, com um desejo de expansão de si, para que as potencialidade de sua personalidade despontem, floresçam, emergindo em direção à superfície. Mas, independentemente do conceito de dignidade própria que cada um possua (dignidade desde dentro), todo indivíduo é, germinalmente, dela merecedor, bem como agente qualificado para demandá-lo do Estado e do outro (dignidade desde fora), pelo simples fato de ser pessoa, independente de condicionamentos sociais, políticos,étnicos, raciais etc. [...] Só há dignidade, portanto, quando a própria condição humana é entendida, compreendida e respeitada, em suas diversas dimensões, o que impõe, necessariamente, a expansão da consciência ética como pratica diuturna de respeito à pessoa humana”. (BITTAR, 2009, p. 301/302). 
Observa-se que os argumentos esboçados pelo mencionado autor reivindicam o esclarecimento da natureza humana para que se torne possível a convivência, assegurada por uma regra de administração, na qual se torne legítima e segura. A inspiração para esse projeto racionalista supera o "contrato de dominação", proposto por Hugo Grócio, porque introduz algo novo na lei natural: a inalienabilidade da pessoa (BLOCH, 1996, p. 61). Por esse motivo, o Contrato Social de Rousseau pode ser descrito como a "Bíblia dos Jacobinos"16.

Esse pressuposto - inalienabilidade da pessoa - se revela pelo apreço à Liberdade ${ }^{17}$. Todos são livres pelo reconhecimento e partilha desse vínculo comum denominado humanidade. Entretanto, adverte Rousseau: não obstante o Homem tenha nascido livre, esse se encontra, ainda, em todos lugares, preso aos grilhões da violência, da miséria, da desigualdade ${ }^{18}$. Não é possível estabelecer um pacto de convivência entre pessoas livres enquanto essa premissa não estiver clara para que possa ser exercitada e reivindicada.

Esse direito não pode estar sob o jugo da força física, da imposição que deslegitima a presença do Outro $^{19}$. Nas palavras de Rousseau, quando todos se tornam servis e obedecem à vontade do soberano, fazem bem, porém no momento em que agem para recobrarem a Liberdade perdida, de acordo com as diretrizes asseguradas pela legislação, percebe-se a conexão de utilidade da justiça entre aquilo que o direito admite e prescreve. Numa expressão do próprio autor: esse direito precisa indicar os mecanismos para reaver a Liberdade ou impedir a existência de critérios que possam subtraí-la (ROUSSEAU, 2013, p. 22).

O agir moral - amparado pela lei, quando possível - desvela não apenas os significados de revoluções ${ }^{20}$ necessárias, mas, também, a necessidade de se controlar, de se propor limites às conquistas históricas no decorrer do tempo, seja pelas relações entre as pessoas ou naquelas entre cidadãos e soberanos. Essa condição não seria possível sem reconhecer a premissa fundamental já mencionada: a inalienabilidade da pessoa ${ }^{21}$.

Reger a pluralidade das diferentes vontades entre homens e mulheres parece um desafio improvável até para o próprio Ícaro. O pensamento de Rousseau consegue, no entanto, retirar o véu que impedia de se enxergar como a associação ${ }^{22}$ entre pessoas, assegurada pelo Direito, se torna viável a fim de garantir a boa convivência. A elaboração de um Contrato Social não se fundamenta no "direito do mais forte" porque essa condição não permite o exercício e reivindicação de direitos os quais sejam expressão de uma autoridade legítima.

16 E complementa Bloch: "[...] The Social Contract (1762) thus became the Bible of the Jacobins, or one might even say, in an anachronist image, that it became the Sermon on the Mount of rejuvenated people". (BLOCH, 1996, p. 61).

17 “[...] É o princípio de que o único fim em função do qual o poder pode ser corretamente exercido sobre qualquer membro de uma comunidade civilizada contra sua vontade, é o de prevenir dano a outros. [...] Uma pessoa não pode correctamente ser forçada a fazer ou deixar de fazer algo porque será melhor para ela que o faça, porque a fará feliz, ou porque, na opinião de outros, fazê-lo seria sensato ou até correcto. [...] A única parte da conduta de qualquer pessoa, com base na qual ela responde perante a sociedade, é que diz respeito aos outros. Na parte da sua conduta que apenas diz respeito a si, a sua independência é, por direito, absoluta. Sobre si, sobre o seu próprio corpo e sua própria mente, o indivíduo é soberano”. (MILL, 2006, p. 39/40).

18 "Concebo na espécie humana duas formas de desigualdade. Uma, que chamo de natural ou física, porque é estabelecida pela natureza e consiste na diferença das idades, da saúde, das forças do corpo e das qualidades do espírito ou da alma. A outra, que pode ser chamada de desigualdade moral ou política, porque depende de uma espécie de convenção e que é estabelecida, ou pelo menos autorizada, pelo consentimento dos homens. Esta consiste nos diferentes privilégios de que gozam alguns em prejuízo dos outros, como ser mais ricos, mais honrados, mais poderosos do que os outros ou mesmo fazer-se obedecer por eles". (ROUSSEAU, 2012, p. 33).

19 “[...] Força é uma potência física, não vejo em absoluto que moralidade pode resultar de seus efeitos. Ceder à força constitui um ato de necessidade, não de vontade; é no máximo um ato de prudência. [...] Convenhamos, pois, que força não faz direito, e que não se é obrigado a obedecer senão às autoridades legítimas". (ROUSSEAU, 2013, p. 24/25).

2o E complementa Cunha: "Crendo na bondade natural do Homem, só corrompida pela sociedade, o autor do mito do bom selvagem, foi um dos cabouqueiros da Revolução Francesa. Desejou que o seu Contrato Social fosse uma refutação do Espírito das Leis de Montesquieu. Na verdade, os dois autores encabeçariam miticamente, para muitos, duas famílias políticas futuras: a liberal e a totalitária”. (CUNHA, 2010, p. 311).

21 "Ó homem, de qualquer região que sejas, quaisquer que sejam as tuas opiniões, escuta: aqui está a tua história, tal como acreditei lê-la, não nos livros de teus semelhantes, que são mentirosos, mas na natureza, que não mente nunca. Tudo o que dela vier será verdadeiro; os tempos de que vou falar são bem remotos. Como mudaste daquilo que eras! É, por assim dizer, a vida da tua espécie que vou descrever segundo as qualidades que recebeste, que tua educação e teus hábitos puderam depravar, mas que não puderam destruir. Há, eu o sinto, uma idade na qual o homem, como individuo, desejaria parar. Tu procurarás a idade na qual desejarias que tua espécie tivesse parado. Descontente com teu estado atual por várias razões que anunciam à tua prosperidade infeliz maiores descontentamentos ainda, talvez quisesses retrogradar e esse sentimento deve constituir o elogio de teus primeiros ancestrais, a crítica de teus contemporâneos e o espanto daqueles que tiverem a infelicidade de viver depois de ti”. (ROUSSEAU, 2012, p. 35).

22 "Ora, como é impossível aos homens engendrar novas forças, mas apenas unir e dirigir as existentes, não lhes resta outro meio, para se conservarem, senão formando, por agregação, uma soma de forças que possa arrastá-los sobre a resistência, pô-los em movimento por um único móbil e fazê-los agir de comum acordo". (ROUSSEAU, 2013, p. 30). 
Essa última expressão citada é o fundamento principal na obra de Rousseau: a autoridade legítima se manifesta unicamente por convenção a partir da vontade (livree) geral dos homens e mulheres ${ }^{23}$. Ninguém entrega - de modo deliberado - a sua autonomia e liberdade para qualquer forma de representação, sejam os soberanos, os aristocratas ou os próprios parlamentos. Segundo o mencionado filósofo, percebe-se que a soma dos esforços justifica e protege a liberdade de cada pessoa. A vontade geral é mais significativa e forte em detrimento á vontade de um único ser humano no sentido de se preservar a inalienabilidade humana.

Os argumentos demonstrados anteriormente podem ser sintetizados pelas palavras de Rousseau (2013, p. 31) a fim de se caracterizar o que seria o Contrato Social: "Cada um de nós põe em comum sua pessoa e toda a sua autoridade, sob o supremo comando da vontade geral, e recebemos em conjunto cada membro como parte indivisível do todo". Unitas multiplex: a pluralidade está na unidade, bem como o inverso também é verdadeiro ${ }^{24}$.

Sob igual critério, não é possível fomentar a associação entre as pessoas e lhes assegurar direitos para que haja uma paz duradoura sob a flâmula da força descrita - e, pior, aceita - da escravidão. A idéia de Liberdade ${ }^{25}$, para Rousseau, é imprescindível para que haja o reconhecimento desse vínculo antropológico comum $^{26}$. Por esse motivo, rememora o autor sobre a importância de se destacar os significados da categoria Alienar.

Essa última expressão mencionada designa o ator de dar ou vender. Na vigência de um Contrato Social nenhum ser humano pode se tornar escravo de outro, seja por entrega gratuita ${ }^{27}$ de si ou pela imposição de sua autoridade sobre seu semelhante, pois, nesse caso, e como se observou nos parágrafos anteriores, não existe algo como o "direito do mais forte". A partir desse argumento, enfatiza o autor: nulo é o direito de escravizar alguém sob a vigência do Contrato Social porque as duas palavras "escravidão" e "direito" excluem-se mutuamente (ROUSSEAU, 2013, p. 28).

Quando um grupo de pessoas se reúne para estabelecer vínculos de convivência assegurados pelo Contato Social, a categoria Alienar denota sentido contrário àquele observado pela escravidão. Nesse momento, "Alienar" precisa ser entendida como doação, pois esse é o comando que se expressa pela reciprocidade de pessoas livres e iguais ${ }^{28}$. A alienação total de cada associado sobre seus direitos em favor de todos se traduz como a perfeita união (ROUSSEAU, 2013, p. 30).

Percebe-se pela obra de Rousseau a importância histórica do Contrato Social como expressão racional de se reconhecer os seres humanos como responsáveis pelas suas decisões, pela sua liberdade e singularidade. A exigência da vontade geral se constitui como a única autoridade legítima capaz de organizar a vida social. Convenciona-se, como pressuposto fundamental desse cenário, a Liberdade em oposição à escravidão, seja de forma gratuita ou imposta pela força.

A Razão, nesse momento de se fixar critérios mínimos para assegurar a convivência sadia e duradoura, venceu. $\mathrm{O}$ estilo poético de Rousseau convence no sentido de se enxergar, com clareza, como a pluralidade de opiniões de pessoas livres e iguais constitui a unidade da vontade geral. Entretanto, os seus escritos, a sua intenção de crer a bondade natural do ser humano, foi, historicamente, distorcida.

Substitui-se a prudência pela intolerância, o pensamento racional pelos fanatismos. Desde elogio

23 E justifica o autor: "Encontrar uma forma de associação que defenda e proteja de toda força comum a pessoa e os bens de cada associado, e pela qual, cada um, unindo-se a todos, não obedeça portanto senão a si mesmo, e permaneça tão livre como anteriormente. Tal é o problema fundamental cuja solução é dada pelo contrato social”. (ROUSSEAU, 2013, p. 30).

24 "In this way, Rousseau contends that the subject does not alienate his freedom, since it remains an equal part of the general will and since an equally large number of wills ally themselves to his will as the number to which he allies himself. Rousseau contends that by virtue of this 'reciprocity' individual freedom remains as it always was: The will of all adjusts itself to the general will'. (BLOCH, 1996, p. 62).

25 "[...] The ideological basis for Rousseau's position unquestionably lies in the principle of individual freedom and its omnipotent power, which penetrates the general will of the community”. (BLOCH, 1996, p. 63).

26 "Renunciar à própria liberdade é o mesmo que renunciar à qualidade de homem, aos direitos da Humanidade, inclusive aos seus deveres”. (ROUSSEAU, 2013, p. 26).

27 "Dizer que um homem se dá gratuitamente é dizer coisa absurda e inconcebível; um tal ato é ilegítimo e nulo, pelo simples fato de não se achar de posse de seu juízo quem isto comete. Dizer a mesma coisa de todo um povo é supor um povo de loucos: a loucura não faz direito". (ROUSSEAU, 2013, p. 25).

28 "Enfim, cada qual, dando-se a todos, não se dá a ninguém, e, como não existe um associado sobre quem não se adquira o mesmo direito que lhe foi cedido, ganha-se o equivalente de tudo o que se perde e maior força para conservar o que se tem". (ROUSSEAU, 2013, p. 31). 
a criticas - severas - acerca do Contrato Social, o referido autor incitou a necessidade das revoluções pela preservação da Liberdade como fundamento inalienável dos seres humanos. Embora já não estivesse mais vivo, contribuiu para que houvesse a Revolução Francesa, bem como à disseminação do terror promovido pelos Jacobinos ${ }^{29}$.

$\mathrm{Na}$ medida em que as sociedades de ampliam e se tornam mais complexas, o Contrato Social não consegue oferecer aquele cenário outrora de organização. A Razão cede espaço para a racionalização. Todos se tornam objetos, se tornam "coisas" para atenderem aos interesses egoístas e indiferentes dos seres humanos. A saturação histórica deste império elaborado pela Razão Instrumental denota a reivindicação de um habitat comum que ultrapassa a postura antropocêntrica.

Quando outros sujeitos são reconhecidos como essenciais para a manutenção da vida, observase a insuficiência de um pacto cuja natureza é exclusivamente antropocêntrica. Nesse momento, surge a indagação: O Contrato Social é suficiente para preservar, também, o mundo natural caracterizado como "ser próprio" junto aos seres humanos? A resposta somente surge pelo esclarecimento do que pode vir a ser um Contrato Natural.

\section{A RAZÃO VENCEU? ELOGIO AO CONTRATO NATURAL}

A substituição da Razão pelo seu caráter instrumental despojou a singularidade da vida. As demandas (infinitas) pelo consumo excessivo transformam (tudo e) todos em mercadorias ${ }^{30}$. O Contrato Social de Rousseau, como projeto racional de preservação da vida comum, aos poucos, esmaece. A postura egoísta transfronteiriça não mede esforços para se perpetuar no tempo e espaço. A pergunta elaborada por Touraine (2002, p. 22) parece oportuna: "Por que chamar de racional, nos dias de hoje, um consumo de massa que corresponde mais à busca de um status social ao desejo de seduzir ou ao prazer estético?"

A cegueira causada pelo crescimento e exploração desmedida dos seres humanos impede de observar que a Terra, o único lar que acolhe uma rica biodiversidade de vidas, não se torna lar comum, mas propriedade de alguns poucos os quais desejam se tornar os Locatários para expulsarem todos os que não podem se tornarem possíveis Locadores. A preservação de um vínculo biológico comum não teria sentido na concepção racional de um projeto antropocêntrico como o Contrato Social.

Esse pacto destina-se tão somente aos seres humanos e sua proteção. Nada fora desse critério (lógico?) pode assumir condição de sujeito a fim de ser preservado dessas ações predatórias, cuja premissa axiológica ainda está no seu caráter utilitário. Se algo (ou alguém) não possuir serventia para viabilizar "os meus interesses", deve-se eliminar. A Natureza ${ }^{31}$ é objeto de infinita exploração humana porque é desprovida de (auto)consciência ou outras formas de comunicação que apresentem semelhante sintonia aos graus de cognição dos seres humanos.

A preservação da biodiversidade na Terra não ocorre apenas nos limites territoriais dos Estados-nação. Não se trata de uma compreensão que se exaure nas competências legais de cidadãos nacionais. A amplitude desta preocupação transborda as fronteiras e se espalha pelo mundo. Reivindica-se o reconhecimento de outro sujeito - não-humano - a fim consolidar perspectivas genuínas de vida compartilhada.

Entretanto, o desejo da paz não se manifesta pelo enunciado do Contrato Social de Rousseau. Não obstante esse início de século XXI enfatize a Natureza como "ser próprio", o qual não deve ser caracterizado como objeto, não existe um instrumento de plena realização dos desejos humanos. O véu en-cobre essa

29 "Na minha opinião, enganam-se os que distinguem a intolerância civil da intolerância teológica. Essas duas intolerâncias são inseparáveis. É impossível viver em paz com gente que se crê danada; amá-la seria como odiar a Deus que a castiga; é absolutamente necessário convertê-la ou puni-la. Onde quer que a intolerância teológica seja admitida, torna-se impossível não haja algum efeito civil; e tão logo este apareça deixa o soberano de ser soberano, mesmo em relação ao poder temporal: a partir de então, os sacerdotes passam a ser os verdadeiros senhores, e os reis apenas os seus oficiais". (ROUSSEAU, 2013, p. 134).

30 As palavras de Serres precisam ser meditadas: "Perdemos o mundo: transformámos as coisas em fetiches ou mercadorias, em apostas dos nossos jogos de estratégia; e as nossas filosofias, acosmistas, sem cosmos, desde há quase há quase meio século, falam apenas de linguagem ou de política, de escrita ou de lógica”. (SERRES, 1994, p. 52).

31 A expressão será utilizada com letra maiúscula neste estudo para determinar a sua caracterização como "ser próprio". 
clareza de proximidade entre a postura antropocêntrica e biocêntrica. Insiste-se no domínio, na Terra como propriedade a ser demarcada e usufruída pelos Locatários para se identificar quem são os possíveis Locadores.

Nesse momento, o(a) leitor(a) indaga-se: De que modo ocorre essa (indevida) apropriação? A resposta parece clara, segundo o pensamento de Serres (2011, p. 12/13): pela poluição. Numa expressão: poluímos para nos apropriarmos da casa comum denominada Terra. Por esse motivo, nas palavras do citado autor, o verbo marcar tem origem nas pegadas deixadas pelos pés no chão de terra, mas se refere, também, ao modo como os animais demarcam e reconhecem o seu habitat.

Essa atitude, sob oângulo dos animais não-humanos, ocorre por meio da utilização de excrementos - duros, fedorentos, muitas vezes - para delimitar aquilo que é próprio e não pode ser reivindicado por outro (SERRES, 2011, p. 11). O domínio é exercitado pela presença de algum sinal biológico característico. Essa ação conserva algo para si como se seu fosse. Nos animais humanos ${ }^{32}$, é possível detectar uma diversidade expressiva dessa tentativa de domínio, especialmente sobre a Natureza: slogans, carimbos, marcas de produtos, entre outros.

Serres (2011, p. 14, grifos do autor da obra), oportunamente, ressalta a afirmação anterior: "o próprio se adquire e se conserva pelo sujo". No âmbito mundial, essa postura de poluir para se apropriar é observada com clareza. Todos os dias, milhares de pessoas consomem diversos produtos, desde comidas produzidas organicamente até instrumentos tecnológicos os quais permitem a sua estadia na mainstream contínua da internet.

Cada um desses produtos seduz na medida em que oportunizam a sensação de se ter o seu domínio, mas trata-se de uma falsa pretensão porque todos exibem as marcas, os slogans próprios dessas mercadorias, mas não é possível adentrar nesses lugares, pois o proprietário já existe. Por esse motivo, o domínio do produto continua daquele que o criou, inventou a sua publicidade, disseminou-a (mundialmente) e, finalmente, fora adquirida por alguém ${ }^{33}$.

Por oposição a essa insistência em se marcar tudo (e todos) pela poluição, surge a necessidade a limpeza. Se poluir significa apropriação, limpar, sob esse argumento, denota a ausência de um proprietário. Esse espaço se torna livre, brevemente, até o momento no qual se exerça o domínio em detrimentos aos outros por meio de uma atitude poluidora.

Os hotéis, por exemplo, demonstram essa afirmação: o seu espaço é acolhedor porque se encontra limpo, despido de quaisquer evidências - especialmente físicas. Ninguém deseja dormir num quarto cujos lençóis estejam impregnados pelo suor, bactérias e germes do antigo hóspede. Não é por outro motivo que se aprecia os serviços de limpeza, pois esses eliminam a presença de um possível proprietário num espaço que, agora, se torna meu (SERRES, 2011, p. 15).

A guerra produzida pelo domínio da ação poluidora intensifica não apenas uma miséria humana, mas contribui, de modo significativo, para a destruição da biodiversidade de vida na Terra. Dominar significa ter um habitat. Nas palavras de Serres (2011, p. 23, grifos do autor da obra): “[...] Os que habitam têm, os que não habitam lugar algum, não têm um ponto, em absoluto. Será que existem ainda? Acabam de decair aquém dos animais".

A Terra é o espaço comum de abundância vital para todos os seres vivos - animais (humanos e não-humanos), vegetais, bactérias, germes, protozoários. Todos comungam um local que acolhe seus (transitórios) hóspedes. É necessário insistir: a Natureza, segundo o pensamento do mencionado autor, se encontra presente no globo, mas essa expressão não indica ausência de proximidade, de omissão dos seres humanos e o planeta. Ao contrário, esse reage globalmente por meio de nossas (impertinentes) ações locais (SERRES, 1994).

A partir desses argumentos, não é possível insistir no domínio de um ambiente, pois a Terra pode,

32 "[...] muitos homens marcam e sujam, conspurcando-os, os objectos que lhes pertencem, para que continuem na sua posse, ou, outros, para que venham a estar". (SERRES, 1994, p. 57).

33 "[...] Usando uma estratégia competente e que passa despercebida - pois exposta ao olhar de todos -, eles dividem com o comprador a propriedade. São ainda mais espertos, eles ficam com ela! De longe, meu carro não anuncia meu nome, quero dizer, o do ingênuo ao estilo Jean-Jacques que pensou tê-lo comprado; o que ele anuncia é a marca do fabricante. Pagamos às montadoras o que compramos, mas, de certa maneira, elas ficam com o que vendem". (SERRES, 2011, p. 38). 
também, dominar. O nosso planeta continuará se desenvolvendo, terá o seu término, mesmo que não exista um humano sequer sob seu território. Novamente, é necessário meditar o pensamento do autor (SERES,1994) citado anteriormente:

Esqueçamos, pois, a palavra ambiente [...]. Ela pressupõe que nós, homens, estamos no centro de um sistema que gravitam à nossa volta, umbigos do universo, donos e possuidores da natureza. Isso lembra uma época passada, em que a Terra [...] colocada no centro do mundo reflectia o nosso narcisismo, esse humanismo que nos promove no meio das coisas ou no seu excelente acabamento. Não. A Terra existiu sem os nossos inimagináveis antepassados, poderia muito bem existir hoje sem nós e existirá amanhã ou ainda mais tarde, sem nenhum dos nossos possíveis descendentes, mas nós não podemos existir sem ela. Por isso, é necessário colocar bem as coisas no centro e nós na sua periferia, ou melhor ainda, elas por toda a parte e nós no seu seio, como parasitas.

Essas afirmações indicam ao jurista as insuficiências históricas do Contrato Social propostos por Rousseau ${ }^{34}$ diante de um pacto mais amplo no qual sugere preservação de todos, mas, também, o reconhecimento da Natureza como "ser próprio"35, o qual pode expulsar os Locadores por seus usos e abusos ou dominá-los.

A Terra, rememora Serres (1994, p. 58), não se comunica ${ }^{36}$ no mesmo grau de cognição dos seres humanos, mas demonstra a força de nossas ligações e interações. Novamente, indaga-se: A Razão venceu? A resposta parece negativa e incita a necessidade de se pensar outro contrato além do social, um que tenha como matriz de significalidade a dimensão ecológica. Por esse motivo, pensa-se no Contrato Natural.

Ao se refletir sobre a importância e a responsabilidade de um vínculo de solidariedade ${ }^{37}$ entre os sujeitos vivos que habitam este Planeta, é necessário destacar que não é possível deduzir abstratamente as dificuldades humanas e não humanas para se insistir numa comunhão de vida planetária, pois quando inexiste o reconhecimento ${ }^{38}$, a proximidade e a responsabilidade pelas ações as diferentes comunicações não ocorrem. O lugar de sentido primário de concretude dessas relações é o cotidiano o qual se torna expressão de um estar-junto-com-o-Outro-no-mundo39. É, aqui, que se observa o sentido de uma Ecologia

34 "No fundo de uma barca, sobre o lago Bienne, entre o céu e a água, entre os pássaros e a vegetação o solitário Jean-Jacques sente a sua existência; cidadão de Genebra, Rousseau assina o Contrato social, pelo menos virtualmente, com seus pares, presentes ou passados. Na natureza, não há multidão, nem Estado; no direito não existe flora nem fauna. De um lado, as coisas; do outro, os homens. Hoje em dia, vivemos obcecados por esse perigoso divórcio acosmista: a história esquece a geografia e nem as ciências sociais nem a política se preocupam com o planeta. Atualmente, não apenas habitamos o planeta como tecemos com ele laços tão globais e cerrados que ele passa a fazer parte de nossos contratos. [...] Se, assim como os animais, emporcalhamos o lugar em que desejamos transformar em nosso nicho exclusivo, a poluição mundial representa o ponto máximo - e, sem dúvida, o fim - da apropriação. Devemos conceber uma nova instituição que poderia ser chamada de Wafel [Water (água), Air (ar), Fire (fogo), Earth (Terra), Life (vida)], na qual o Homo políticus acolheria os elementos e os seres vivos, quase sujeitos não apropriáveis porque formam o habita comum da humanidade. Sob risco iminente de morte, precisamos decidira paz entre nós para salvaguardar o mundo e a paz com o mundo a fim de nos salvar". (SERRES, 2008, p. 208/209).Grifos originais da obra estudada.

35 "O que éa natureza? Em primeiro lugar, o conjunto das condições da própria natureza humana, as suas limitações globais de renascimento ou de extinção, a estalagem em que lhe dá alojamento, aquecimento e comida; além disso, ela priva-a disso, logo que abuse. Condiciona a natureza humana que, a partir desse momento, passa a condicioná-la. A natureza conduz-se como um sujeito". (SERRES, Michel, 1994, p. 62).

36 "How to speak this voice? How to speak in several voices, that of things, that of knowledge, of emotions, of each and everyone, that of humanity? Will we, one day, by dint of listening to the voices of Biogea, say this language? Like Aldo Leopold, Empedocles wanted to think like the mountain; to live like the earth on fire, the fire that warms with love and consumes with hate: to think like de elements of a science that was being born in its totality. Like I would like to think". (SERRES, 2010, p. 79).

37 "[...] Enquanto os seres humanos continuam sendo uma ameaça para si mesmos, eles estão ameaçando, em grau crescente, as condições naturais das quais dependem. Isso exige uma ampliação do conceito de solidariedade”. (BOSSELMANN, 2015, p. 182).

38 "Quaisquer que sejam os meios de reconhecimento, uma de suas características primeiras não deve ser esquecida: a demanda por ele sendo de natureza inesgotável, sua satisfação não pode jamais ser total ou definitiva. [...]. A fome por reconhecimento é desesperadora. [...]. Mesmo o reconheci- mento de conformidade, mais tranquilo do que aquele obtido através da distinção, exige que, constantemente, recomecemos sua busca. Nossa incompletude, portanto, é não apenas constitutiva, mas também incurável (ou, então, ficaríamos 'curados', também, de nossa humanidade)”. (TODOROV, 2014, p. 129).

39 "A vivência do eu plural, em suas diversas direções, fomenta um politeísmo cultural dinâmico e presente. Ao mesmo tempo, forma-se um tempo particular ocasionado por esse viver o estar-junto. A vida múltipla e fragmentada que permeia um sentido vivente não possui uma unidade delimitada e específica, todavia constitui uma unicidade irrefutável”. (AQUINO, 2016, p. 42). 
da vida cotidiana como pressuposto de uma Ecologia integral ${ }^{40}$.

Nessa linha de pensamento, o Contrato Natural é caracterizado como simbiótico, ou seja, reconhece a necessidade do respeito e não admitiria as formas de domínio, de demarcação, segundo os argumentos citados neste tópico. Trata-se de um contrato cujo fundamento é as relações amistosas que evitam o surgimento e a proliferação de parasitas. Esses, nas palavras do autor estudado, são vorazes, devoram tudo sem oferecer nada em retorno.

O hospedeiro, ao contrário, doa tudo sem necessitar nada para si. Nessa linha de pensamento, ressalta Serres (1994, p. 66): “[...] o direito de simbiose define-se pela reciprocidade: aquilo que a natureza dá ao homem é o que este lhe deve dar a ela, tornada sujeito de direito". Observa-se, a partir dessa leitura, que o Contrato Natural estabelece a importância do mundo - e suas profundas singularidades - na sua totalidade. Mais que atitudes responsáveis, precisa-se de virtudes como o cuidado ${ }^{41}$ que os seres humanos precisam ter com a nossa "Casa Comum" sul-americana.

Se o Contrato Natural se revela como simbiótico, existe um elemento cuja ausência torna impossível conceber a sua existência e sua práxis na vida de todos os dias: o Amor. Sem essa condição, não existe elo forte suficiente para ampliar os diálogos entre a dimensão "global" e "local" de todos os hóspedes acolhidos na Terra, qual seja, o Amor ${ }^{42}$. No pensamento de Serres (1994, p. 8o/81), o Amor desdobra-se em duas leis: a) "amai-vos uns aos outros e; b) "amemos o mundo".

Na primeira lei, percebe-se a conexão de uma conduta que ame os seres vivos pela sua proximidade, mas, também, no sentido global, uma postura amorosa que acolhe a humanidade, caso alguém não acredite em Deus (SERRES, 1994, p. 80). Não adianta, contudo, amar a todos e explorá-los para atender aos desejos pessoais. Essa é a hipocrisia, enfatiza o autor, disseminada pelos moralistas.

A segunda lei enuncia o amor ao mundo. Não se pode exaltar uma paixão apenas pelo território natal, pois, nesse caso, a Terra seria desprezada e causaria mais conflitos entre todos. Precisa-se, na advertência de Serres (1994, p. 82), amar nossos dois pais - natural e humano, bem como nossa mãe, também natural e humana. Nessa linha de pensamento, o amor ao território local e à Terra possibilita acolher o próximo e o estranho, recupera a legitimidade do singular diante do todo. Esse é o fomento para estabelecer, pelo Contrato Natural, uma paz sadia e duradoura.

O Contrato Natural é escrito, sob a premissa do amor, em todas as partes do mundo. Revela outro estágio de humanidade: Hominescência. Todas as formas de interação, de cuidado, de preservação com a Terra denotam esse reconhecimento do nosso planeta como "ser próprio". A amplitude e estimulo dessas convergências amistosas, amorosas e menos dominadoras representa a persistência de se esclarecer, historicamente, esse amor proxêmico. A UNASUL surge como expressão do Contrato Natural.

\section{A UNASUL COMO EXPRESSÃO DO CONTRATO NATURAL: SURGE A UTOPIA CONCRETA}

Nenhuma Utopia, como se depreende da linguagem comum, reina de modo perpétuo nos limites do mundo as ideias, mas transforma realidades na medida em que permeia as esperanças humanas de que algo modifique as nossas realidades, tal como se imaginou com o descobrimento da jovem - e até aquele momento desconhecida - América. Tempo, Espaço e Vontade: ingredientes para a reconstrução

\footnotetext{
40 "Dado que tudo está intimamente relacionado e que os problemas atuais requerem um olhar que tenha em conta todos os aspectos da crise mundial, proponho que nos detenhamos agora a refletir sobre os diferentes elementos duma ecologia integral, que inclua claramente as dimensões humanas e sociais". (FRANCISCO, 2015, p. 85).

41 "Pensar, considerar, planejar e empreender com foco no futuro só será possível a partir da adição de um forte substrato ético como guia das ações. Afinal, a consideração plena com a casa comum requer cuidado, solidariedade e empatia”. (BODNAR; PASSOS DE FREITAS; SILVA, 2017, p. 66)

42 Embora, Ferry privilegia a dimensão do humanismo, deve-se refletir sobre as suas palavras acerca de um novo imperativo categórico pautado no Amor: "Aja de maneira a desejar ver as decisões que você toma se aplicarem também aos seres que mais ama". (FERRY, 2013, p. 244). Grifos originais da obra estudada.
} 
das utopias sul-americanas ${ }^{43}$.

$\mathrm{O}$ (a) leitor(a) consegue identificar neste texto as principais características enunciadas pelos tipos de contratos apresentados: O Contrato Social e o Contrato Natural. Os seus fundamentos teóricos demonstram a importância histórica na tentativa de se estabelecer pactos necessários os quais conduzam aos diferentes modos de reconhecimentos sobre os diferentes sujeitos que habitam a Terra.

A Natureza, como se percebeu, não se limita a ser objeto de exploração infinita do ser humano, tampouco permanece silente quando o animal humano tenta dominá-la. Não se trata empreender ações de domínio, mas de compreender os modos de comunicação a fim de se corroborar relações amistosas globais e locais - entre as pessoas e a Terra. Por esse motivo, insiste-se numa responsabilidade do cuidado, da empatia, da solidariedade que se manifesta pela Ecologia

Por esse motivo, emprega-se, para este tópico, a categoria Utopia Concreta de Ernst Bloch. O Contrato Natural não se apresenta como sonho distante, irrealizável. Esse pacto no qual amplia - de modo simbiótico e amoroso - o acolhimento de todos. O seu desenvolvimento ocorre pelas diferentes grafias as quais demonstrem essa relação de proximidade e cuidado, sejam nas terras aradas, nos canais de irrigação, nos vinhedos, na preservação da fauna, entre outros (SERRES, 2003, p. 220).

A Utopia Concreta expressa que o desejável não se limita aos domínios da abstração, mas se torna fenômeno "de carne e osso" ${ }^{44}$. A expressão jurídica mais apropriada para caracterizar o Contrato Natural é o Tratado Constitutivo da UNASUL (2014, grifo do autor), o qual pode se perceber pela leitura de seu preâmbulo, bem como de seus objetivos, especialmente a letra "g":

[...] que tanto a integração quanto a união sul-americanas fundam-se nos princípios basilares de: irrestrito respeito à soberania, integridade e inviolabilidade territorial dos Estados; autodeterminação dos povos; solidariedade; cooperação; paz; democracia, participação cidadã e pluralismo; direitos humanos universais, indivisíveis e interdependentes; redução das assimetrias e harmonia com a natureza para um

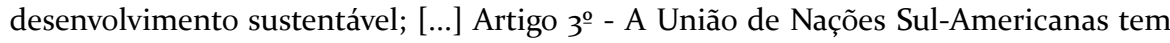
como objetivos específicos: [...] g) a proteção da biodiversidade, dos recursos hídricos e dos ecossistemas, assim como a cooperação na prevenção das catástrofes e na luta contra as causas e os efeitos da mudança climática;

A UNASUL constitui uma tentativa de elaborar sua identidade continental a partir de uma filosofia sul-americana na qual retrate esse resgate do vínculo entre os seres humanos e a Natureza. O pensamento de Serres indica a necessidade de se compreender como o Contrato Natural possibilita compreender o mundo natural como "ser próprio".

Dentre os povos sul-americanos, os andinos estão em maior sintonia com a Natureza e possibilitam o cumprimento desinteressado e amoroso do citado contrato a fim de acolher todos os seres vivos. Essa filosofia é denominada como Buen Vivir.

Viver e conviver, nessa linha de pensamento, são as estratégias nas quais se perpetuam os diálogos entre a trindade indivíduo-sociedade-espécie e a Terra descritos, microscopicamente, na América do Sul (HUANACUNI MAMANI, 2010, p. 32). Essa é busca pelo equilíbrio e harmonia naquilo que se torna fundamental, comum ao bem-viver de todos com tudo.

O horizonte inalcançável, na qual se afasta a cada passo dado, precisa de perseverança, paciência

43 "Aventuremos uma hipótese: porque a América teve desde a sua origem, primeiro aos olhos dos europeus e logo depois dos próprios americanos, os dois ingredientes básicos da, espaço e tempo, quer dizer, um território onde se fundar e uma história com um passado por recuperar ou um futuro para projetar-se com facilidade, isso proporcionou desde sua integração à história do Ocidente a objetivação da utopia”. (AINSA, 2006, p. 137/138).

44 "[...] O ponto de contato entre sonho e vida, sem o qual o sonho produz apenas utopia abstrata e a vida, por seu turno, apenas trivialidade, apresenta-se na capacidade utópica colocada sobre os próprios pés, a qual está associada ao possível-real. [...] aqui teria lugar o conceito de utópico-concreto, apenas aparentemente paradoxal, ou seja, um antecipatório que não se confunde com o sonhar utópico abstrato, [...]". (BLOCH, 2005, v.1, p. 145). 
e compreensão sobre os novos sujeitos que dialogam com os seres humanos, embora a América do Sul possua diversidade cultural acentuada e agravada por um cenário histórico de dominação e exploração. Essa relação amorosa de proximidade entre os humanos e a Natureza retrata como esse horizonte já esteve mais distante.

Viver bem ${ }^{45}$ não significa viver melhor, pois essa segunda expressão revela a lógica na qual o Ocidente se encontra caracterizado: trata-se da postura de sobrevivência, de intensas - e profundas - desigualdades as quais geram as misérias humanas globais. Busca-se ter mais poder, mais fama. As pessoas e o mundo natural tornam-se reificados e ampliam todas as formas de misérias e desigualdades. O advérbio de intensidade "mais" tentar suprir algo impossível na condição humana: a sua insaciabilidade em tudo querer dominar e consumir.

Viver melhor, para Huanacuni Mamani (2010, p. 32), significa disseminar a exploração ambiental ilimitada, o progresso dissociado dos meios e fins, o incremento à acumulação de bens materiais, ou seja, retorna-se para a postura egoísta, esquece-se dos vínculos de proximidade entre o local e o global e se deteriora o indivíduo, a sociedade, a espécie, bem como as paisagens naturais, os animais, a vida que pulsa silenciosamente. A Terra se torna inabitável.

A UNASUL representa a esse espírito do "viver bem" na medida em que exige a participação dos seres humanos frente aos desafios de integração antropológica e biológica no continente. Observa-se que esse espaço de integração continental possibilita a Eficácia e Eficiência daquela compreensão apresentada por Serres e complementada pela filosofia andina do buen vivir. Fora desse contexto, é possível que o Contrato Natural não torne possível as esperança de acolhimento entre todos na Terra.

Nenhum outro espaço geopolítico amplia a postura biocêntrica como fonte de irradiação desse outro momento histórico de reconhecimento da Natureza como "ser próprio". Insiste-se: O Contrato Natural é expressão de uma Utopia Concreta na medida em que se materializa por meio dos objetivos determinados pela UNASUL e pela filosofia andina do Buen Vivir. Sem a UNASUL, o Contrato Natural não se apresenta como opção aperfeiçoada do projeto racionalista e antropocêntrico do Contrato Social.

O Contrato Natural não é uma abstração vazia, uma idéia sem sentido, ao contrário, representa o devir para uma época saturada das "promessas de amante" 46 enunciadas pelos seres humanos e para apenas seres humanos. O Contrato Natural é essa aposta no improvável, numa Utopia Concreta ${ }^{47}$ que, pouco a pouco e silenciosamente, se manifesta na vida de todos os dias.

\section{CONSIDERAÇÕES FINAIS}

Observa-se, na linguagem comum, como a categoria Utopia justifica - e reforça - a ausência de ações os quais permitam que a esperança se torne "de carne e osso". Essa última expressão mencionada esperança - revela-se como princípio político no qual não se observa passividade, mas a ação prudencial, persistente, capaz de animar a renovação de vida entre os seres vivos e arquitetar uma harmonia universal.

45 "En la visión del vivir bien, la preocupación central no es acumular. El estar en permanente armonía con todo nos invita a no consumir más de lo que el ecosistema puede soportar, a evitar la producción de residuos que no podemos absorber con seguridad. Y nos incita a reutilizar y reciclar todo lo que hemos usado. En esta época de búsqueda de nuevos caminos para la humanidad, la idea del buen vivir tiene mucho que enseñarnos. El vivir bien no puede concebirse sin la comunidad. Irrumpe para contradecir la lógica capitalista, su individualismo inherente, la monetarización de la vida en todas sus esferas, la desnaturalización del ser humano y la visión de la naturaleza como "un recurso que puede ser explotado, una cosa sin vida, un objeto a ser utilizado". (HUANACUNI MAMANI, 2010, p. 33).

46 Expressão retirada de Warat na qual o autor assemelha os fenômenos que ocorrem em ramos do conhecimento como as promessas que os amantes fazem a si, sabendo que não poderão cumpri-las. (WARAT, 2002, p. 13/14).

47 E rememora Bloch: "[...] A carência daquilo que sonhamos não dói menos, ao contrário. Isso, portanto, impede que se acostume com a privação. Tudo o que fere, oprime e enfraquece deve desaparecer. [...] O sonhar, sobretudo, sempre sobreviveu ao fugaz cotidiano individual. Nele procura-se algo diferente da vontade de se trajar e espelhar o que o patrão deseja. Nele se esboça no ar uma imagem maior, ponderada a partir do desejo. Mesmo com essa ponderação, muitas vezes se cometeram enganos, mas quando estes ocorrem não é possível manter a ilusão com tanta freqüência. Tampouco se pode contentá-la. Sua vontade objetiva algo mais, e tudo o que conquista tem gosto desse algo mais. De modo que a vontade não apenas tenta viver além de suas próprias condições, mas além das circunstâncias precárias". (BLOCH, 2006, v.2, p. 9/10). 
A convivência desejável, manifestada como improbabilidade, aos poucos, aparece diante dos olhos de todos.

A melodia entoada por uma Utopia Concreta, segundo se pode depreender das lições de Bloch, não é um sonho de pura abstração. Ao contrário, é possível escutar, com clareza, como as notas musicais intensificam a passagem desse silêncio originário de princípios dedutivos, de uma Razão incapaz de ultrapassar as fronteiras do argumento lógico, ao estrondo da experiência de re-encontro do ser humano com a Natureza. Essa sensação de pertença, de acolhimento amoroso se amplia por todo o território terrestre.

Essa condição sinaliza que a construção das novas utopias sul-americanas, estudadas a partir do Contrato Natural, não depende tão somente de interesses econômicos e geopolíticos, porém uma nova consciência acerca de nossa "Casa Comum", a qual é impossível de se caracterizar apenas a partir das relações humanas. A Ecologia da Vida Cotidiana, dessa unidade vital na América do Sul entre Homem e Natureza, é apenas o primeiro passo desse tempo de maturação entre o ideal e o real.

Nesse novo cenário, cujos atores conseguem, apesar das dificuldades, ouvirem e serem ouvidos, a paz não pode ser fenômeno originário de um pacto no qual preserve exclusivamente os homens e mulheres e possibilite o seu domínio sob todas as criaturas como se estivessem na Terra para serem exploradas, indefinidamente, e saciarem a vontade (infinita) dos seres humanos.

O Contrato Social, apesar de suas distorções históricas, conseguiu estabelecer parâmetros mínimos para a convivência entre as pessoas ao reivindicar a partilha desse vínculo comum denominado Humanidade. A singularidade da vida espalha-se por todos que se encontram em situação semelhante, ou seja, compartilham alegrias, tristezas, angústias, sonhos. No entanto, a sua referência dedutiva, esboçada como projeto racional antropocêntrico não consegue dinamizar a complexidade de novas relações amistosas as quais aparecem num planeta sem fronteiras.

Por esse motivo, o Contrato Natural se apresenta como uma idéia própria para esclarecer e preservar relações as quais extrapolem tão somente as vias de comunicação entre os seres humanos. O sentido do cuidado deixa de ser nebuloso para se tornar uma Utopia Concreta, principalmente pela integração continental fomentada pela UNASUL.

O Contrato Natural se torna expressão utópica concreta por meio da UNASUL e a filosofia andina do Buen Vivir. Essa proximidade des-cobre a amplitude de um conviver o qual havia deixado de produzir significados porque se expulsou a Natureza de nosso contato em decorrência de sua incapacidade comunicativa. A racionalização exacerbada do Ocidente nos tornou cegos e surdos diante das suplicas e convites para se abraçar a totalidade do mundo.

Talvez, não seja tarde demais para se experimentar novas utopias, tampouco para que haja nossa redenção perante o único lugar neste universo que, por enquanto, abriga e acolhe a nossa vida. Nunca se compreendeu que somos hóspedes neste planeta, mas se preferiu ser um parasita desmedido. Por esse motivo, o Contrato Natural é a força regenerativa o qual preserva uma (nova) relação entre sujeitos e não mais entre um sujeito e uma pluralidade de objetos.

\section{REFERÊNCIAS}

AINSA, Fernando. A reconstrução das utopias. Tradução de Antônio Sidekum. São Leopoldo, (RS): Nova Harmonia, 2006.

AQUINO, Sérgio Ricardo Fernandes de. Por uma cidadania sul-americana: fundamentos para sua viabilidade na UNASUL por meio da ética, fraternidade, sustentabilidade e política jurídica. Säarbrucken: Novas Edições Acadêmicas, 2014. 
AQUINO, Sérgio Ricardo Fernandes de. Raízes do direito na pós-modernidade. Itajaí, (SC): UNIVALI, 2016.

BITTAR, Eduardo C. B. O direito na pós-modernidade: e reflexões frankfurtianas. 2. ed. Rio de Janeiro: Forense Universitária, 2009.

BLOCH, Ernst. Natural Law and human dignity. Translated by Dennis J. Schmidt. Third printing. Baskerville: MIT press, 1996.

BLOCH, Ernst. O princípio esperança. Tradução de Nélio Schneider. Rio de Janeiro: EdUERJ/ Contraponto, v.1, 2005.

BLOCH, Ernst. O princípio esperança. Tradução de Werner Fuchs. Rio de Janeiro: EdUERJ/Contraponto, v. 2, 2006.

BODNAR, Zenildo; PASSOS DE FREITAS, Vladimir; SILVA, Kaira Cristina. A epistemologia interdisciplinar da sustentabilidade: por uma ecologia integral para a sustentação da casa comum / The interdisciplinary epistemology of sustainability: for an integral ecology for the support of the common house. Revista Brasileira de Direito, Passo Fundo, v. 12, n. 2, p. 59-7o, dez. 2016. ISSN 2238-0604. Disponível em: <https:// seer.imed.edu.br/index.php/revistadedireito/article/view/1558>. Acesso em: o6 ago. 2017.

BOSSELMANN, Klaus. O princípio da sustentabilidade: transformando direito e governança. Tradução de Phillip Gil França. São Paulo: Revista dos Tribunais, 2015.

CUNHA, Paulo Ferreira da. Filosofia política: da antiguidade ao século XXI. Lisboa: Imprensa NacionalCasa da Moeda, 2010.

DOSTOIÉVSKI, Fiódor. O grande inquisidor. In: Clássicos do conto russo. Tradução de Boris Schnaiderman et al. 2. ed. São Paulo: Editora 34, 2017.

FERRY, Luc. Do amor: uma filosofia para o século XXI. Tradução de Rejane Janowitzer. Rio de Janeiro: DIFEL, 2013.

FRANCISCO. Laudato si: sobre o cuidado da casa comum. São Paulo: Paulus/Loyola, 2015.

HUANACUNI, Fernando. Buen vivir/ Vivir bien: Filosofía, políticas, estrategias y experiencias regionales andinas. Peru: CAOI, 2010.

LÉVINAS, Emmanuel. Totalidade e infinito. Tradução de José Pinto Ribeiro. Lisboa: Edições 7o, 2000 .

MILL, John Stuart. Sobre a liberdade. Tradução de Pedro Madeira. Lisboa: Ediçoes 7o, 2006.

MORIN, Edgar. Os sete saberes necessário à educação do futuro. Tradução de Catarina Eleonora e Jeanne Sawaya. 4. ed. São Paulo/Brasília: Cortez/UNESCO, 2001.

PASOLD, Cesar Luiz. Metodologia da pesquisa jurídica: teoria e prática. 12. ed. São Paulo: Conceito Editorial, 2011. 
REALE, Miguel. O direito como experiência: introdução à epistemologia jurídica. 4. tir. São Paulo: Saraiva, 2010.

ROSA, Alexandre Morais da. Garantismo jurídico e controle de constitucionalidade material. Florianópolis: Habitus, 2002.

ROUSSEAU, Jean-Jacques. A origem da desigualdade entre os homens. Tradução de Ciro Mioranza. São Paulo: Lafonte, 2012.

ROUSSEAU, Jean-Jacques. O contrato social: e outros escritos. Tradução de Rolando Roque da Silva. 22. ed. São Paulo: Cultrix, 2013.

SERRES, Michel. Biogea. Translated by Randolph Burks. Minneapolis: Univocal, 2010.

SERRES, Michel. Hominescências: o começo de uma outra humanidade? Tradução de Edgard de Assis Carvalho e Mariza Perassi Bosco. Rio de Janeiro: Bertrand Brasil, 2003.

SERRES, Michel. O contrato natural. Tradução de Serafim Ferreira. Lisboa: Instituto Piaget, 1994.

SERRES, Michel. O mal a limpo: poluir para se apropriar? Tradução de Jorge Bastos. Rio de Janeiro: Bertrand Brasil, 2011.

SERRES, Michel. Ramos. Tradução de Edgard de Assis Carvalho. Rio de Janeiro: Bertrand Brasil, 2008.

TAYLOR, Charles. A ética da autenticidade. Tradução de Luís Lóia. Lisboa: Edições 70, 2009.

TOURAINE, Alain. Crítica da modernidade. Tradução de Elia Ferreira Edel. 7. ed. Petrópolis, (RJ): Vozes, 2002.

UNASUL. União das Nações Sul-americanas. Tratado constitutivo da UNASUL. Disponível em: <http:// www.itamaraty.gov.br/temas/america-do-sul-e-integracaoregional/unasul/tratado-constitutivo-daunasulunas >. Acesso em: 11 de out. 2017. 